\title{
Polychaete assemblages as indicators of habitat recovery in a temperate estuary under eutrophication
}

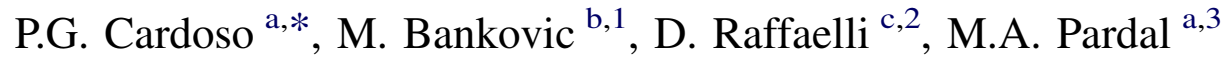 \\ ${ }^{a}$ IMAR - Institute of Marine Research, Department of Zoology, University of Coimbra, 3004-517 Coimbra, Portugal \\ ${ }^{\mathrm{b}}$ Biology Department, University of Padua, via Colombo, 3-35121 Padua, Italy \\ ${ }^{\mathrm{c}}$ Environment Department, University of York, Heslington, York YO10 5DD, UK
}

Received 2 March 2006; accepted 3 August 2006

Available online 12 September 2006

\begin{abstract}
From 1980 to 2000, the Mondego estuary (Portugal) suffered dramatic changes due to eutrophication, leading to a decline in seagrass beds and changes in community structure, namely a decline in species richness and replacement of herbivores by detritivores. Because the conservation status of the estuary was being compromised, a restoration project was implemented in 1998 in order to restore the original natural seagrass habitat. This project included several restoration/management measures, including the protection of the remaining seagrass patches and improvement of the hydraulic conditions through modifying sluice opening regimes, thereby reducing the nutrient loading in the southern arm of the estuary. In addition, several stakeholder forums were convened to inform local people of the ecological and economic importance of the area. In this paper we evaluate the success of this management plan as judged by changes in the polychaete assemblages.

In the year following implementation of the restoration measures, the total biomass of polychaetes increased markedly, a pattern also seen in the overall macrobenthic community. Biomass recovery was faster and more pronounced compared to density recovery, probably because many larger species were able to attain adult body size (e.g. Hediste diversicolor). The polychaetes Alkmaria romijni and Capitella capitata, considered as indicators of nutrient enrichment and pollution of estuarine systems, gradually declined over time. A general increase in species diversity was observed after the application of the restoration/management measures.

These changes indicate that the restoration project has been successful and that polychaetes can be considered representative indicators of the wider macrobenthic community, with considerable savings in time and effort for monitoring programmes.

(C) 2006 Elsevier Ltd. All rights reserved.
\end{abstract}

Keywords: polychaete assemblages; biological indicators; seagrass beds; eutrophication; restoration

\section{Introduction}

Declines in environmental quality and seagrass beds, often associated with increased eutrophication are of increasing concern world-wide, especially in densely populated coastal areas (Everett, 1994; Schramm and Nienhuis, 1996; Raffaelli et al., 1998; Cloern, 2001). Ecological changes include the

\footnotetext{
* Corresponding author.

E-mail address: gcardoso@ci.uc.pt (P.G. Cardoso).

${ }^{1}$ E-mail address: mira_bancovic@yahoo.co.uk (M. Bankovic).

2 E-mail address: dr3@york.ac.uk (D. Raffaelli).

${ }^{3}$ E-mail address: mpardal@ci.uc.pt (M.A. Pardal).
}

replacement of perennial macrophytes and slow-growing macroalgae by fast-growing macroalgae, as seen in the Mondego estuary (Portugal). Here, in addition to the seagrass decline (Pardal et al., 2000; Cardoso et al., 2004a, 2005), eutrophication has led to marked changes in macrobenthic communities, including a decline in species richness and shifts in trophic structure, i.e. the replacement of herbivores by detritivores together with a significant increase in small deposit-feeding polychaetes (Cardoso et al., 2004a; Verdelhos et al., 2005).

A restoration programme (including physical protection of the remaining seagrass bed, improvement of water circulation, modification of the sluice-opening regime and increased awareness of local people of the importance of this ecosystem) 
was implemented in 1998 in order to restore the original seagrass bed and the overall quality of the estuary. The success of this programme is evaluated in the present paper through changes in the polychaete assemblage of the estuary over a 10-year period. Polychaetes are an important component of benthic communities, because of their high species richness, their high biomass and density, and their high level of tolerance to adverse effects (pollution and natural disturbance) (Méndez et al., 1998; Omena and Creed, 2004; Tomassetti and Porrello, 2005). Here we assess whether monitoring the system using this taxon alone is sufficient to capture the main temporal signals in the broader macrofaunal assemblage and for the estuary as a whole. If so, this would have implications for reducing the time, effort and financial costs for documenting all taxa within the system.

\section{Materials and methods}

\subsection{Study site}

The Mondego estuary on the Atlantic coast of Portugal $\left(40^{\circ}\right.$ $08 \mathrm{~N}, 8^{\circ} 50 \mathrm{~W}$ ) is a temperate estuary, comprising two arms, a northern and a southern, separated by an alluvium-formed island (Murraceira Island) (Fig. 1). The two arms exhibit different hydrological characteristics. The northern arm is deeper (4-8 $\mathrm{m}$ during high tide, tidal range $1-3 \mathrm{~m}$ ) and constitutes the principal navigation channel and the location of the

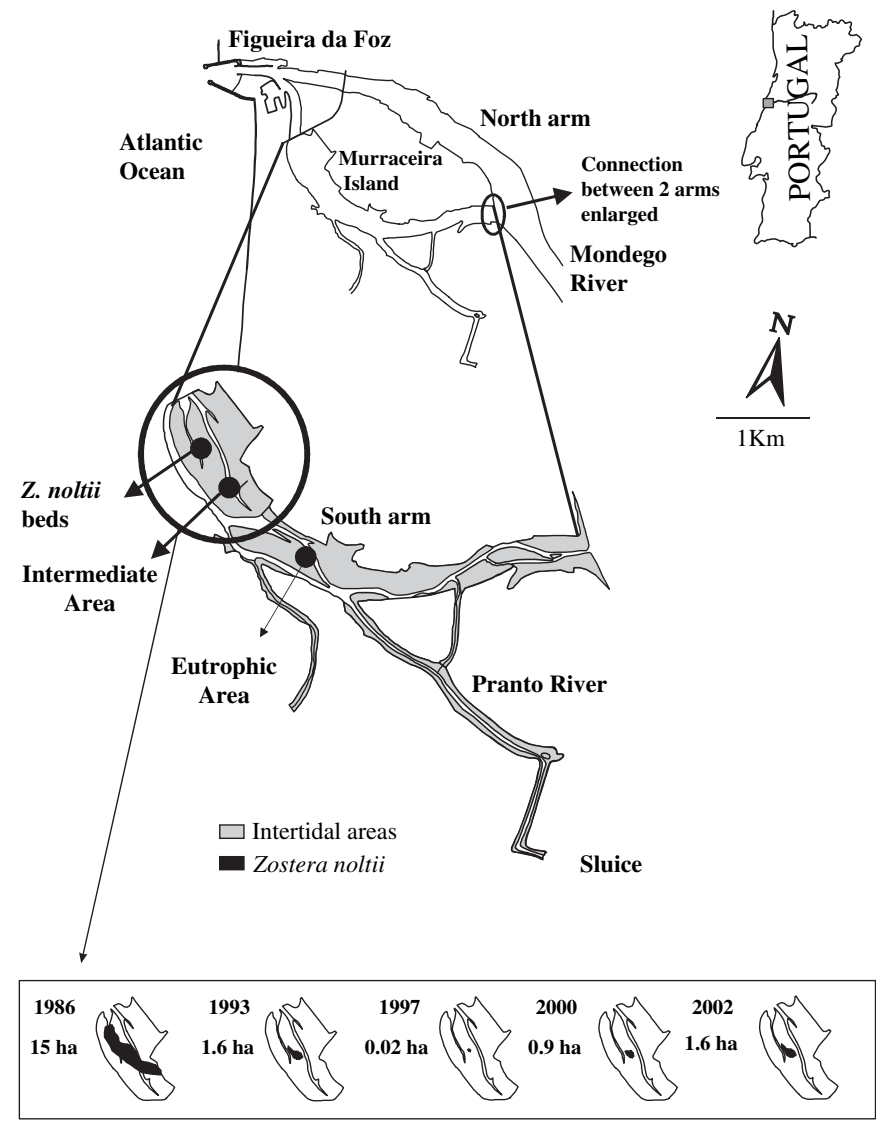

Fig. 1. Location of the study areas along the eutrophication gradient of the south arm of the Mondego estuary.
Figueira da Foz harbour. The southern arm is shallower (2$4 \mathrm{~m}$ during high tide, tidal range 1-3 m) and until 1998 was almost silted up in the upstream areas, causing the freshwater of the Mondego River to flow mainly through the northern arm. Circulation in the southern arm was mostly dependent on the tides and on the freshwater input from the Pranto River. The discharge from this small tributary is controlled by a sluice and is regulated according to the irrigation needs of the Mondego valley rice fields. Since 1984, several interventions were made along the river bed and the Mondego valley in order to improve irrigation efficiency of the agriculture fields. They included construction of channels, regularization of margins (to reduce flooding of the fields), construction of sluices to regulate the water level inside the fields and intensification of land use. All these actions together with the impact of industrial and aquaculture activities within the estuary increased eutrophication, reducing the extent and biomass of the seagrass Zostera noltii bed in the southern arm (Cardoso et al., 2004a; Pardal et al., 2004; Cardoso et al., 2005; Verdelhos et al., 2005). In 1998, the IMAR (Institute of Marine Research) jointly with the Ministery of Environment and in collaboration with farmers, fishermen and other interested local people decided to apply several measures in order to recover the original seagrass bed and the environmental quality of the system. The hydraulic regime in the southern arm was improved by enlarging the connection between the two arms by dredging a small area between those two. The Pranto sluiceopening regime was changed so that most of the freshwater from the Pranto River was diverted to the northern arm, reducing the nutrient loading in the southern arm. In addition, the remaining seagrass patches were protected with wooden stakes to prevent further disturbance by fishermen digging in the sediment for bait and cockles, and several stakeholder forums were convened to apprise local people of the ecological and economic importance of the seagrass bed (Cardoso et al., 2005; Verdelhos et al., 2005). These two combined actions allowed local people to understand the real importance of the seagrass habitat and avoid going inside that protected area.

\subsection{Sampling and laboratory procedures}

Samples were taken at three different areas in the southern arm: (1) Zostera noltii bed, towards the marine end of the estuary, where the seagrass $Z$. noltii is present; (2) an intermediate area, located just upstream of $Z$. noltii bed, a muddy flat containing some rhizomes of Zostera in the sediment; and (3) a eutrophic area, a sand-muddy flat in the inner part of the estuary (Fig. 1). In the 1980s, the eutrophic area was covered by rooted macrophytes, but with the increased eutrophication during the 1990s, Z. noltii declined progressively. This area is now covered seasonally by green macroalgae, especially Ulva sp. (Pardal et al., 2000; Martins et al., 2001; Cardoso et al., 2002). In the 1980s, the Z. noltii bed occupied a broad expanse along the southern arm (15 ha) reaching the innermost parts of the estuary. By the mid-1990s, Z. noltii had become restricted to a small patch (0.02 ha) located 

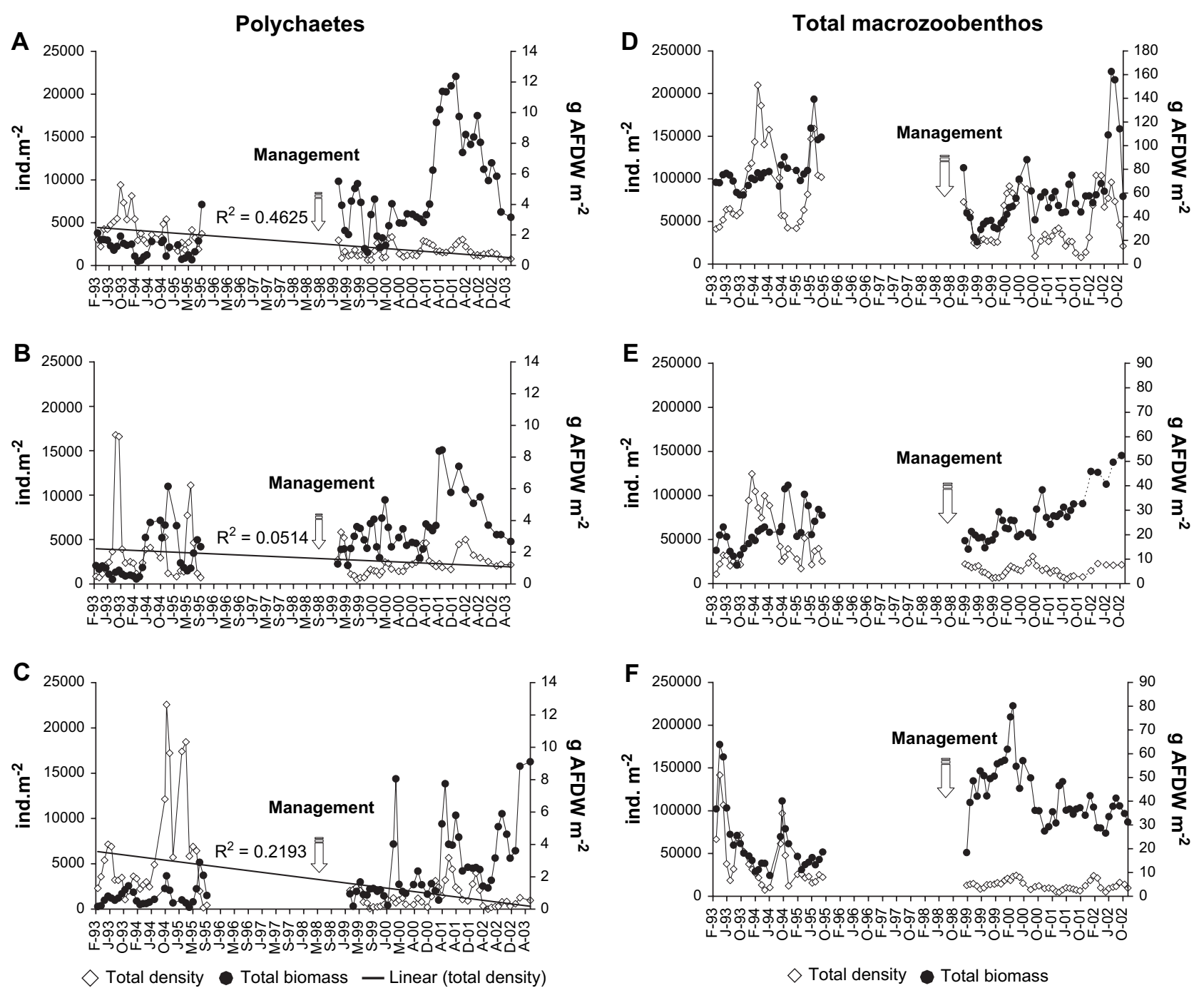

Fig. 2. Variation of total density and biomass (using moving averages) of the polychaete assemblages (A-C); and the entire macrobenthic community (D-F) in the 3 sampling stations. (A, D) - Zostera noltii bed; (B, E) - Intermediate area; and (C, F) - Eutrophic area.

downstream, having been replaced elsewhere by blooms of opportunistic green algae.

The polychaete assemblages were sampled from January 1993 to September 1995 and again from February 1999 to May 2003. Samples (including macrophytes, macroalgae and fauna) were collected fortnightly in the first 18 months and monthly during the rest of the study period. At each study site and on each sampling occasion, 6 to 10 cores $(13.5 \mathrm{~cm}$ diameter) were taken to a depth of $20 \mathrm{~cm}$. Samples were washed in estuarine water through a $500 \mu \mathrm{m}$ mesh, the material retained preserved in $4 \%$ buffered formalin and later transferred to $70 \%$ ethanol. The fauna was identified to the lowest possible taxon and counted. Polychaete biomasses were determined as ash free dry weight (AFDW) after oven drying at $60^{\circ} \mathrm{C}$ for $72 \mathrm{~h}$ and combustion at $450{ }^{\circ} \mathrm{C}$ for $8 \mathrm{~h}$.

\subsection{Data analysis}

The diversity of the polychaete assemblages in the three areas was assessed as total number of species, the Shannon-Wiener (log base 2), Simpson's D and Pielou's evenness measures (Krebs, 1999).

Differences between polychaete samples were explored using non-metric Multi Dimensional Scaling (MDS) (Clarke and Gorley, 2001; Clarke and Warwick, 2001). Numbers of individuals for each sample were square-root transformed prior to analysis in order to reduce the presence of abundant species (Clarke and Warwick, 2001).

\section{Results}

\subsection{Changes in polychaete assemblage versus total those in the macrozoobenthic community}

\subsubsection{Total density and biomass}

Polychaetes represent a small portion of the entire community ( $<10 \%$ of total density). Total density and biomass of polychaetes showed different patterns during the study period. For the three sampling areas total density declined throughout the 10-year period, as is indicated by the trend lines shown in 


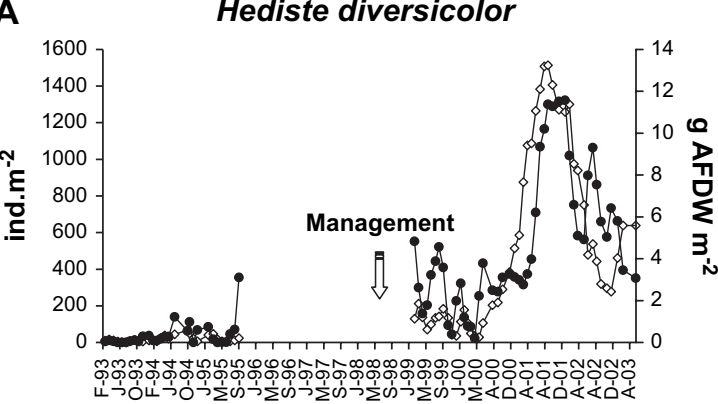

B

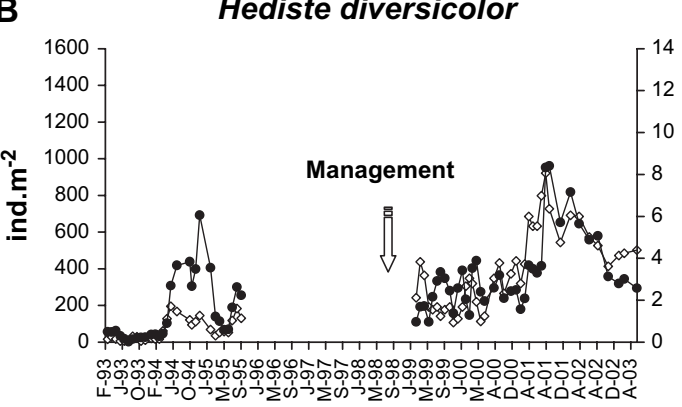

C

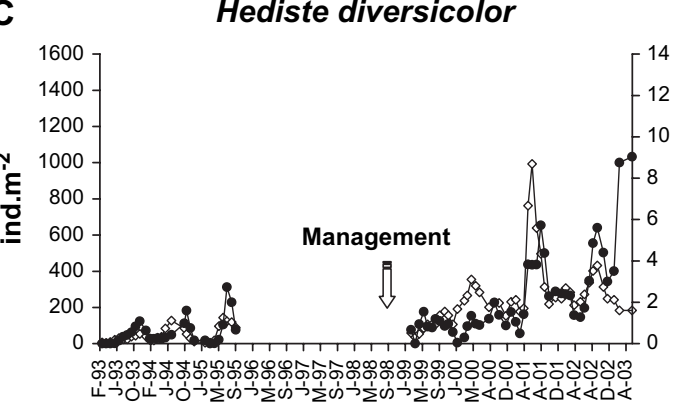

$\triangle$ Total density Total biomass
D

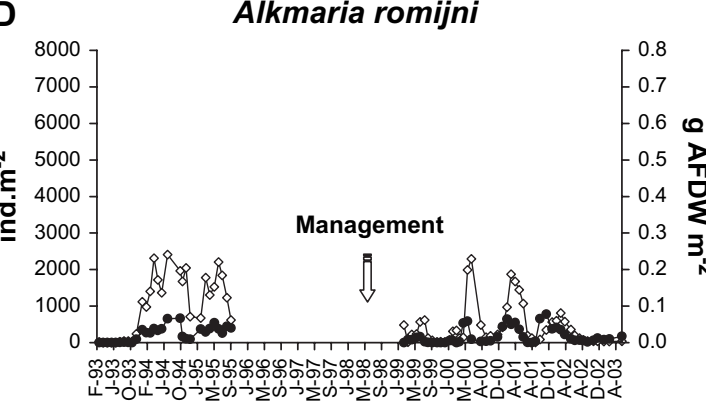

E

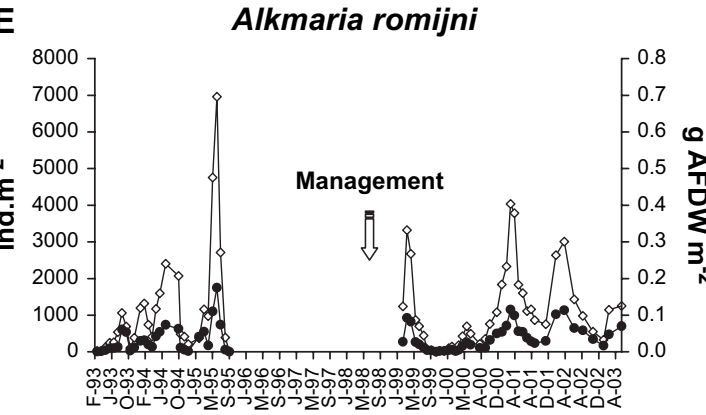

F

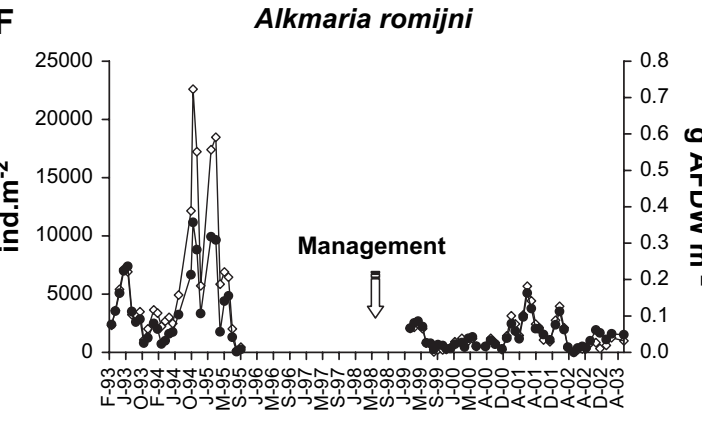

$\diamond$ Total density Total biomass
$\mathbf{G}$

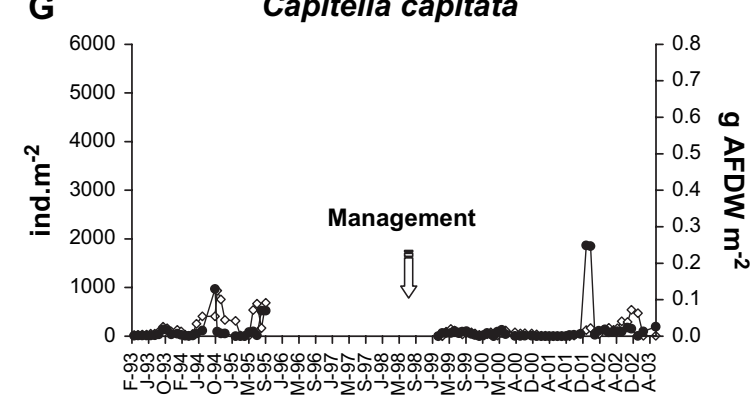

H

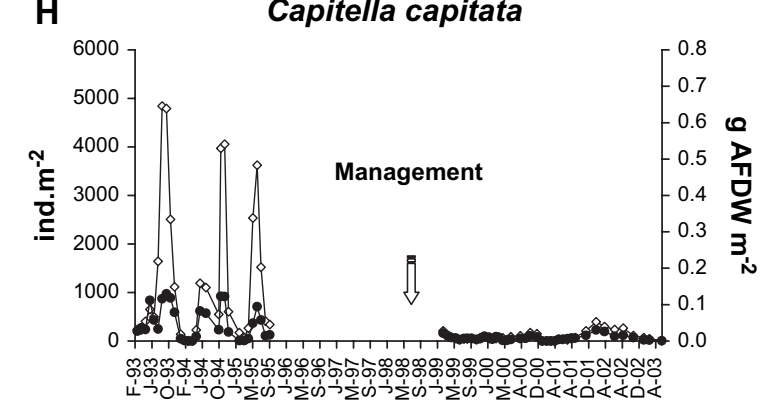

I

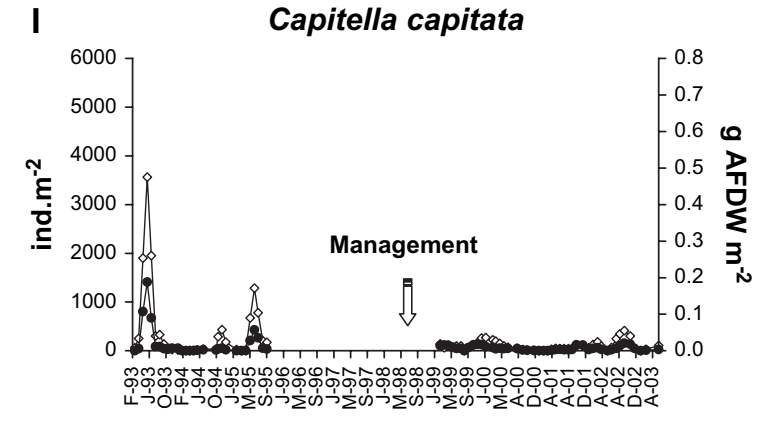

$\diamond$ Total density Total biomass

Fig. 3. Variation of total density and biomass (using moving averages) of three main species of polychaetes (Hediste diversicolor, Alkmaria romijni and Capitella capitata) in the three sampling areas. A $-H$.

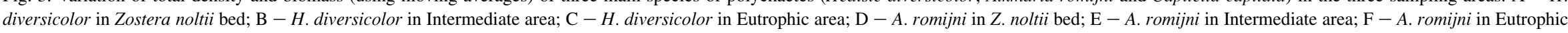
area; $\mathrm{G}-C$. capitata in $Z$. noltii bed; and $\mathrm{H}-$ C. capitata in Intermediate area; $\mathrm{I}-C$. capitata in Eutrophic area. 
the graphs, whilst total biomass showed an opposite trend (Figs. 2A-C). There was a marked increase in total biomass after the application of restoration/management measures, for all the areas, this being more pronounced in the Zostera noltii bed since the beginning of 2001 (Fig. 2A) (Wilcoxon two sample test, $Z$. noltii bed $W=522, P<0.05$; Intermediate area $W=651, P<0.05$; Eutrophic area $W=644, P<0.05$ ). This recovery pattern was affected by extreme flooding of 2000/2001 (see Cardoso et al., 2005) which delayed the recovery process. The patterns seen for polychaetes are similar to those for the broader macrobenthic community (Figs. 2D-F).

\subsubsection{Changes in individual polychaete species}

The dynamics of the three most abundant polychaete species, Hediste diversicolor, Capitella capitata and Alkmaria romijni were analysed in detail. $H$. diversicolor is responsible for 80-90\% of the total polychaete biomass. The density and biomass of this species significantly increased throughout the study period, especially after the implementation of restoration/management measures (Figs. 3A-C). Significant differences in density were observed between the pre- and post-management period for all the three areas (Wilcoxon two sample test, Zostera noltii bed $W=458.5, P<0.05$; Intermediate area $W=473.5$, $P<0.05$; Eutrophic area $W=488, P<0.05$ ).

Capitella capitata and Alkmaria romijni both decreased in density and biomass over the study period (Figs. 3D-I).
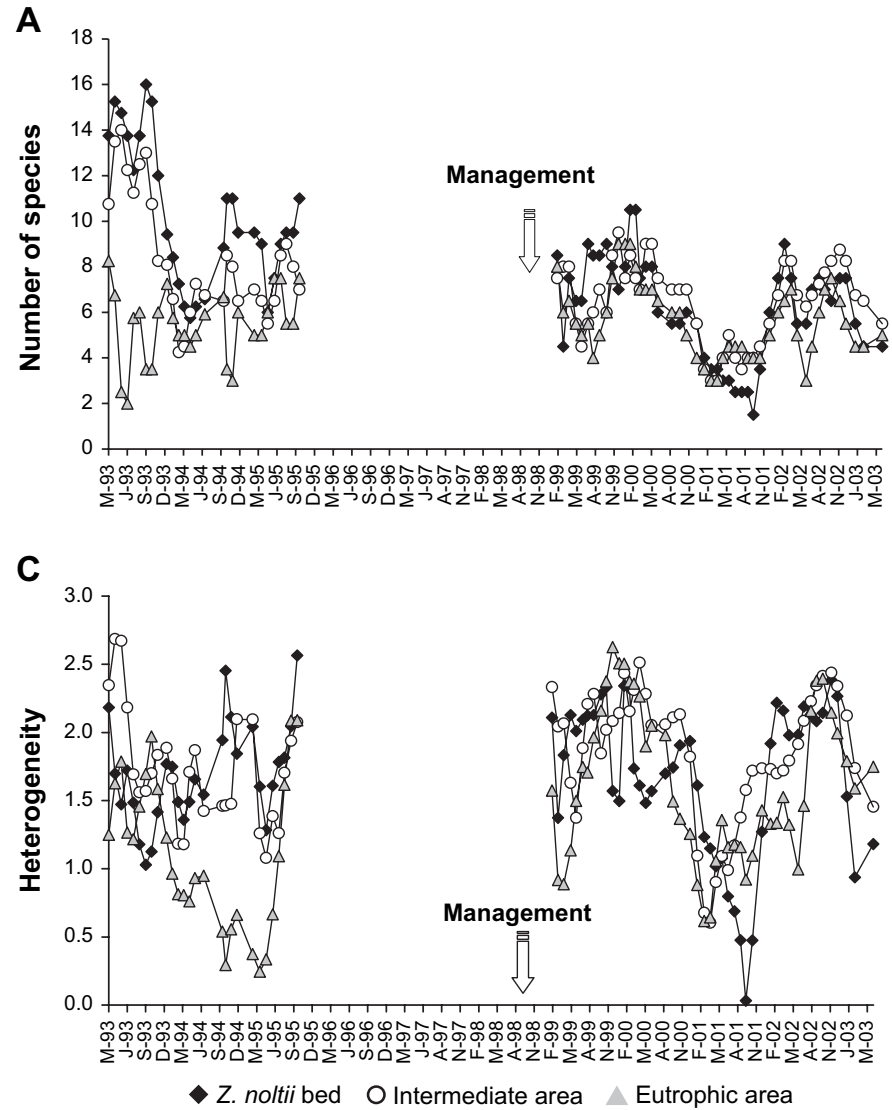

Significant differences in density were observed between the pre- and post-management periods (Wilcoxon two sample test, $C$. capitata: Zostera noltii bed $W=1343.5, P<0.05$; Intermediate area $W=1437.5, P<0.05$, A romijni: $Z$. noltii bed $W=1313.5, P<0.05$; Eutrophic area $W=1587, P<0.05$ ).

\subsection{Changes in diversity}

Species richness declined during the pre-management period, increasing slightly after management measures were introduced, declining again during 2000-01, due to extreme floods (Cardoso et al., 2005), and only starting to recover in 2002. In the pre-management period, the Zostera noltii bed always had more species than the intermediate and eutrophic areas. In the post-management period, these differences decreased (Fig. 4A). In the pre-management period, evenness was higher in the seagrass bed and intermediate area compared to the eutrophic area (Fig. 4B). After management evenness increased in all the three areas, the eutrophic area becoming much closer to the other two study areas. The Shannon-Wiener index (Fig. 4C) followed a similar pattern to that of evenness, and, as expected, Simpson's D index (dominance) showed the opposite pattern, as would be expected (Fig. 4D). For the eutrophic area, dominance declined throughout the study period.

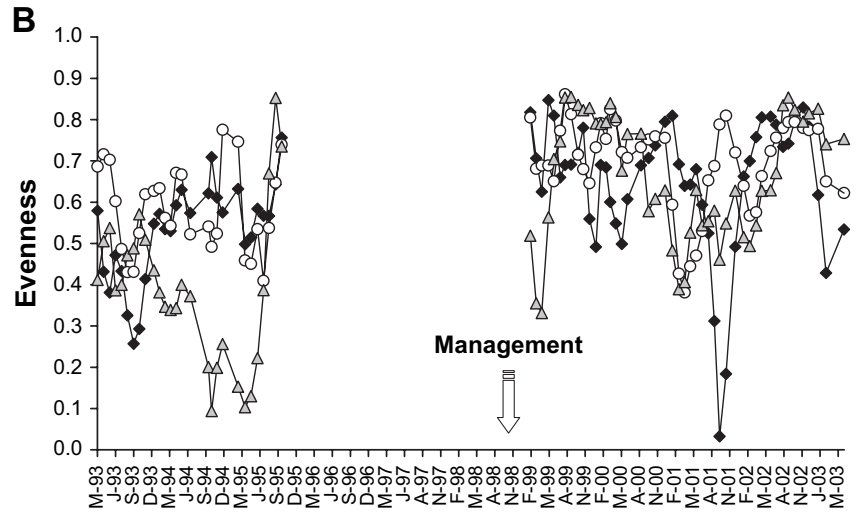

D

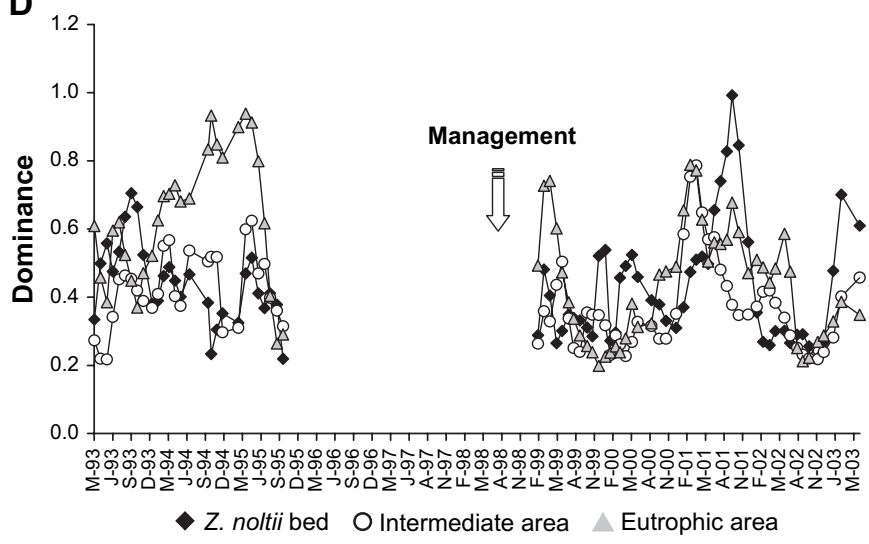

Fig. 4. Variation of the biological indices (using moving averages) in the three sampling stations from 1993 to 2003. (A) - Number of species; (B) - evenness; (C) - Shannon-Wiener index; and (D) - Simpson index. 


\subsection{MDS analysis}

Regarding the MDS plots, for both polychaete and total macrobenthic assemblages, for the three sampling areas, there is a clear separation between samples from the pre- and postmanagement periods (Figs. 5A-F). In addition, we can observe a separation between the 1993 samples from those of the subsequent years. Also, for the post-management period, the 2001 samples are quite isolated from the others, though this pattern is more visible for the Zostera noltii bed, as is highlighted (envelopes) in Figs. 5A,D. Differences between pre- and postmanagement periods were explored further by ANOSIM. This confirmed significant differences between them for both assemblages and for all the 3 areas (polychaete $Z$. noltii bed, $R=0.47$, $P<0.05$; polychaete intermediate area, $R=0.41, P<0.05$; polychaete eutrophic area, $R=0.48, P<0.05$; total macrobenthos $Z$. noltii bed, $R=0.505, P<0.05$; total macrobenthos intermediate area, $R=0.477, P<0.05$; total macrobenthos eutrophic area, $R=0.364, P<0.05$ ).

\section{Discussion and conclusions}

The restoration programme implemented in the Mondego estuary in the late 1990s included a set of restoration measures, such as the controlled use of fertilisers in the agriculture fields located upstream, the improvement of water circulation by enlarging the connection between the two arms, a better management of sluice openings, which led to strong modifications of the physico-chemical features of the estuary (lower turbidity, lower suspended organic matter and lower re-mineralization)

\section{Polychaetes}
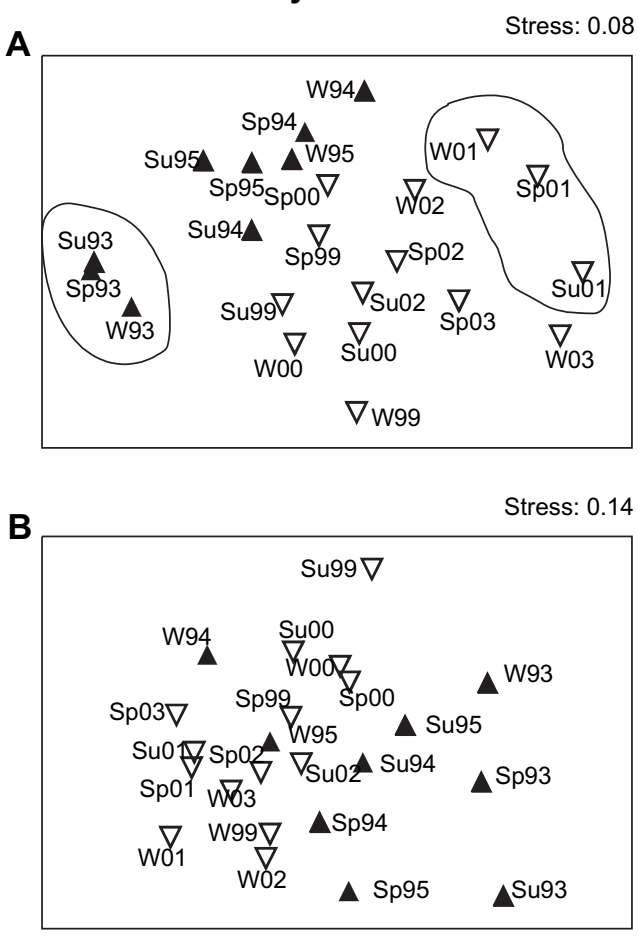

c

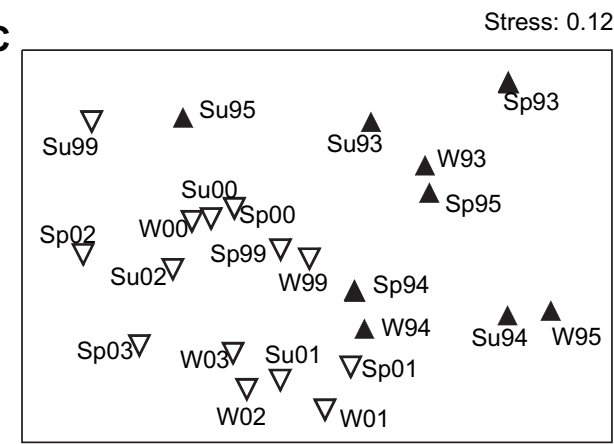

$\Delta$ Pre-management period

$\nabla$ Post-management period
Total macrozoobenthos
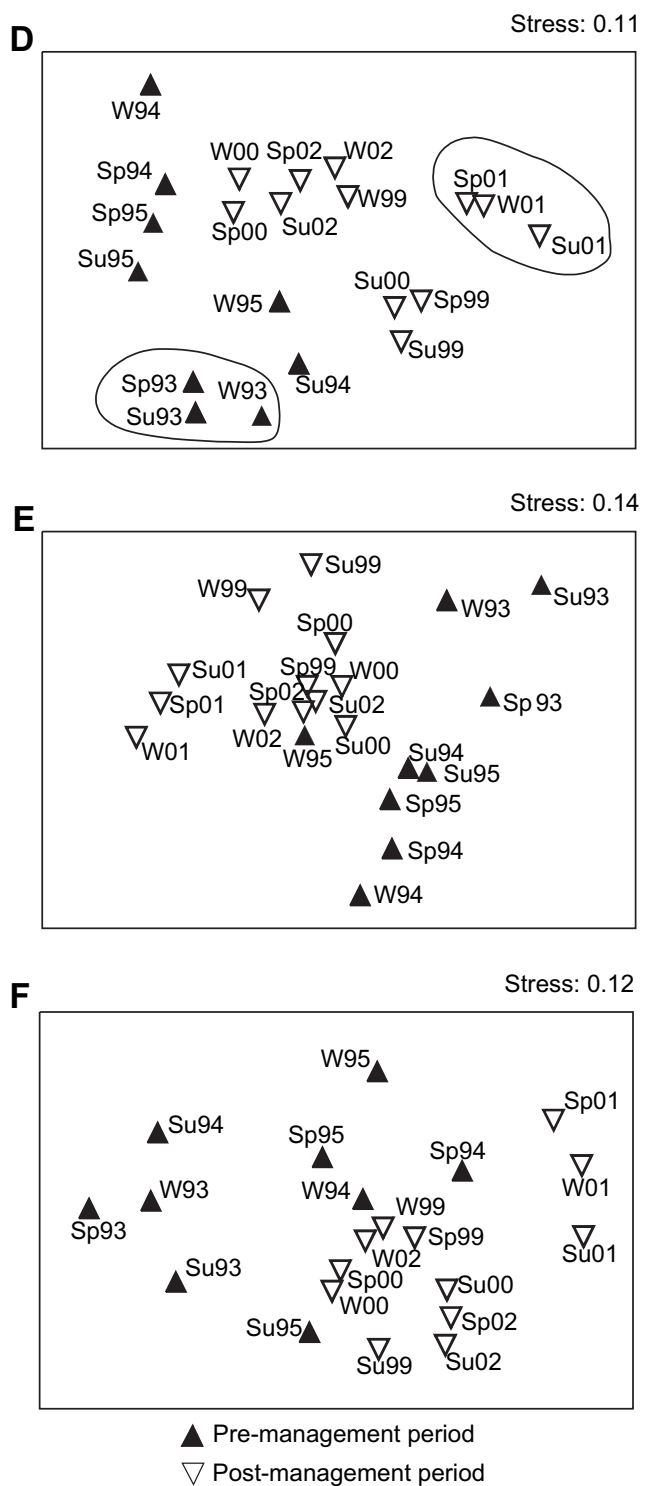

Fig. 5. Two-dimensional MDS ordination plots of polychaete and total macrobenthic assemblages. (A, D) - Zostera noltii bed; (B, E) - Intermediate area; and (C, F) - Eutrophic area. 
(Lillebø et al., 2004), in turn reflected in the dynamics of the primary producers and macrofauna (Cardoso et al., 2005; Verdelhos et al., 2005). Previous studies have noted a reduction in nutrient concentration (and in the $\mathrm{N} / \mathrm{P}$ ratio) in the postmanagement period which limited blooms of green macroalgae (Cardoso et al., 2005; Verdelhos et al., 2005). The seagrass Zostera noltii benefited from these measures, especially the disappearance of algal blooms and gradually recovered both in areal extent and biomass (Cardoso et al., 2005; Verdelhos et al., 2005).

Concerning the polychaete taxon alone, it revealed to be adequate to hold the main temporal indications in the broader macrofaunal community and for the estuary as a whole. The total macrobenthic community and the polychaete assemblage showed similar patterns over time, including a decline in density and a marked increase in biomass after management was introduced for all the three study areas. This is in contrast to observations by Essink (2003) in the Ems estuary, where there was a positive correlation between the broader macrozoobenthic community and polychaete biomass and the amount of organic matter. In the Mondego, early colonizers were mostly small-sized species with fast growth rates, which reached high densities and with high production rates, such as Capitella capitata and Alkmaria romijni. As the community recovered, the larger slowly growing species replaced the opportunists, and these species had a faster recovery of the biomass compared to density. In the absence of macroalgal blooms and anoxic conditions, these species could grow to adult size, as seen for Hediste diversicolor. This species is also tolerant to hypoxia, anoxia and is commonly found under algal mats (Pearson and Rosenberg, 1978; Norkko and Bonsdorff, 1996), but unlike $C$. capitata, seems able to take advantage of less stressful conditions (Cardoso et al., 2004b), possibly because of its better competitive ability and its capacity to feed as an omnivore, predator, suspension feeder and deposit feeder (Norkko et al., 2000). In contrast to previous studies (e.g. Pearson and Rosenberg, 1978), the present paper suggests that in the Mondego estuary, H. diversicolor is not an indicator of organic enrichment. By comparison, $A$. romijni and $C$. capitata are considered good indicators of organically enriched habitats (Méndez et al., 1998; Cardoso et al., 2004b; Tomasseti and Porrello, 2005), and these declined markedly through time, indicating improvement of the system. After the implementation of the restoration/management plan, diversity also increased, mainly through changes in evenness, but species richness also showed some signs of recovery, especially after the intense floods of 2000/2001. During that period (2000/2001) a great part of the polychaete species disappeared, just in 2002 they seemed to recover and reappear. In general, the seagrass bed always had a higher species richness compared to the other two areas, consistent with the more complex habitat structure created by the presence of rooted macrophytes (Omena and Creed, 2004), and the higher sediment stability, food abundance and protection that seagrasses can offer (Duarte, 2002).

We conclude that the restoration measures put in place for the Mondego have been at least partly successful, since environmental conditions are improving better and the macrophyte Zostera noltii is slowly recovering. Most importantly, the polychaete assemblages are becoming more structured, showing higher species diversity and appear to be a good indicator of overall change in the macrofaunal assemblage and the successional state of the estuary as a whole. This taxon alone is sufficient to capture the main signals in the broader macrobenthic community, thereby reducing the time, effort and resources demand by a full analysis of all the species in the system.

\section{Acknowledgements}

This work was supported by FCT (Fundação para a Ciência e Tecnologia) through a $\mathrm{PhD}$ grant attributed to P. G. Cardoso (SFRH/BD/5350/2001). The authors are indebted to all the colleagues that assisted in the field and lab work.

\section{References}

Cardoso, P.G., Lillebø, A.I., Pardal, M.A., Ferreira, S.M., Marques, J.C., 2002. The effect of different primary producers on Hydrobia ulvae population dynamics: a case study in a temperate intertidal estuary. Journal of Experimental Marine Biology and Ecology 277, 173-195.

Cardoso, P.G., Pardal, M.A., Lillebø, A.I., Ferreira, S.M., Marques, J.C., Raffaelli, D., 2004a. Dynamic changes of seagrass assemblages under eutrophication and implications for recovery. Journal of Experimental Marine Biology and Ecology 302, 233-248.

Cardoso, P.G., Pardal, M.A., Raffaelli, D., Baeta, A., Marques, J.C., 2004b. Macroinvertebrate response to different species of macroalgal mats and the role of disturbance history. Journal of Experimental Marine Biology and Ecology 308, 207-220.

Cardoso, P.G., Brandão, A., Pardal, M.A., Raffaelli, D., Marques, J.C., 2005. The resilience of Hydrobia ulvae populations to anthropogenic and natural disturbances. Marine Ecology Progress Series 289, 191-199.

Clarke, K.R., Gorley, R.N., 2001. Primer v5: User Manual/Tutorial. Primer-E Ltd, Plymouth.

Clarke, K.R., Warwick, R.M., 2001. Change in Marine Communities. An Approach to Statistical Analysis and Interpretation, second ed. Primer-E Ltd, Plymouth.

Cloern, J.E., 2001. Our evolving conceptual model of the coastal eutrophication problem. Marine Ecology Progress Series 210, 223-253.

Duarte, C.M., 2002. The future of seagrass meadows. Environmental Conservation $29,192-206$.

Essink, K., 2003. Response of an estuarine ecosystem to reduced organic waste discharge. Aquatic Ecology 37, 65-76.

Everett, R.A., 1994. Macroalgae in marine soft-sediment communities: effects on benthic faunal assemblages. Journal of Experimental Marine Biology and Ecology 175, 253-274.

Krebs, C.J., 1999. Ecological Methodology, second ed. Addison-Welsey Educational Publishers, Inc, Menlo Park, CA, 620 pp.

Lillebø, A.I., Neto, J.M., Flindt, M.R., Marques, J.C., Pardal, M.A., 2004. Phosphorous dynamics in a temperate intertidal estuary. Estuarine, Coastal and Shelf Science 61, 101-109.

Martins, I., Pardal, M.A., Lilleb $\varnothing$, A.I., Flindt, M.R., Marques, J.C., 2001. Hydrodynamics as a major factor controlling the occurrence of green macroalgal blooms in a eutrophic estuary: a case study on the influence of precipitation and river management. Estuarine, Coastal and Shelf Science $52,165-177$.

Méndez, N., Flos, J., Romero, J., 1998. Littoral soft-bottom polychaete communities in a pollution gradient in front of Barcelona (Western Mediterranean, Spain). Bulletin of Marine Science 63, 167-178. 
Norkko, A., Bonsdorff, E., 1996. Population responses of coastal zoobenthos to stress induced by drifting algal mats. Marine Ecology Progress Series $140,141-151$.

Norkko, J., Bonsdorff, E., Norkko, A., 2000. Drifting algal mats as an alternative habitat for benthic invertebrates: species-specific responses to a transient resource. Journal of Experimental Marine Biology and Ecology 248, 79-104

Omena, E., Creed, J.C., 2004. Polychaete fauna of seagrass beds (Halodule wrightii Ascherson) along the coast of Rio de Janeiro (Southeast Brazil). Marine Ecology 25, 273-288.

Pardal, M.A., Marques, J.C., Metelo, I., Lillebø, A.I., Flindt, M.R., 2000. Impact of eutrophication on the life cycle, population dynamics and production of Ampithoe valida (Amphipoda) along an estuarine spatial gradient (Mondego estuary, Portugal). Marine Ecology Progress Series 196, 207-219.
Pardal, M.A., Cardoso, P.G., Sousa, J.P., Marques, J.C., Raffaelli, D., 2004. Assessing environmental quality: a novel approach. Marine Ecology Progress Series 267, 1-8.

Pearson, T.H., Rosenberg, R., 1978. Macrobenthic succession in relation to organic enrichment and pollution of the marine environment. Oceanography and Marine Biology Annual Review 16, 229-311.

Raffaelli, D.G., Raven, J.A., Poole, L.J., 1998. Ecological impact of green macroalgal blooms. Oceanography and Marine Biology 36, 97-125.

Schramm, W., Nienhuis, P.H. (Eds.), 1996. Marine Benthic Vegetation. Recent Changes and the Effects of Eutrohication. Springer, Berlin, $465 \mathrm{p}$.

Tomassetti, P., Porrello, S., 2005. Polychaetes as indicators of marine fish farm organic enrichment. Aquaculture International 13, 109-128.

Verdelhos, T., Neto, J.M., Marques, J.C., Pardal, M.A., 2005. The effect of eutrophication abatement on the bivalve Scrobicularia plana. Estuarine, Coastal and Shelf Science 63, 261-268. 